\title{
A Resonant Series Counterpulse Technique for High Current Opening Switches
}

\author{
Edwin van Dijk \\ Laboratory for Power Electronics and Electrical Machines, \\ Delft University of Technology, Mekelweg 4, NL-2628 CD Delft, the Netherlands \\ Peter van Gelder \\ TNO PML-Pulse Physics Laboratory, Schoemakerstraat 97, NL-2628 VK Delft, the Netherlands
}

\begin{abstract}
A counterpulse technique for the controlled interruption of very high currents in inductive storage pulsed power systems is described and analysed, and some simulation results of its performance are presented. The accompanying circuit comprises a pre-charged capacitor bank, connected in series with the inductive load, which has to be provided with a current pulse. Upon actuation, a resonant counterpulse current is created in the opening switch, connected in parallel with the current source and the load. In this way, the opening switch is opened at low current. A separate closing switch prevents closing of the opening switch at high voltage. Operation of the opening switch, often a mechanical switch, at low current and low voltage prevents arc erosion of the contacts.

The advantage of this circuit compared to other counterpulse circuits is that the capacitor bank does not experience a voltage reversal. Electrolytic capacitors, which have a high energy density, are applied. The remaining energy of the capacitor bank after opening the opening switch, is transferred to the load. The required initial voltage of the capacitor bank is only a few hundred volts, whereas it may be above a kilovolt in other circuits.

Another advantage of the method described here is that the load does not experience a pre-current, causing unwanted preheating of the load, before the resonant current is activated.

At the moment, work is being performed at the Pulse Physics Laboratory to develop the resonant series counterpulse circuit for use with rail accelerators, which must be supplied with current pulses in the millisecond range up to the mega-ampere level.
\end{abstract}

\section{INTRODUCTION}

High current opening switches are used in pulsed power systems where magnetic energy stored in an inductor must be transferred to a load in the form of current pulses of short duration and high amplitude [1]-[4]. An electrical energy source, consisting of a homopolar generator and a storage inductor, is shorted by an opening switch and the source current is flowing through the switch. The load is connected in parallel to the switch, as shown in Fig. 1. Opening and closing the switch forces a current pulse to flow through the load. The load is usually inductive, for example: rail accelerators, free electron lasers, particle accelerators, coils for high pulsed magnetic fields.

At the Pulse Physics Laboratory, an electromechanical high current opening switch [5] is applied to commutate current to a rail accelerator. The energy source consists of a compact pulsed homopolar generator with a storage inductor in series [6]. The kinetic energy of rotation of the homopolar generator is stored as magnetic energy in the inductor. The requirements for the high current opening switch are very severe. It must be able to conduct currents up to the megaampere level for several tenths of a second, open within a

Manuscript received April 14, 1994.

E. van Dijk, e-mail evdijk@et.tudelft.nl, phone +31-15-697018, fax +31-15 782968; P. van Gelder, phone +31-15-697015, fax +31-15-621268. This work is funded by TNO Defence Research, the Netherlands. millisecond, remain open for a few milliseconds and withstand a voltage of a few kilovolts, and close again. This cycle has to be performed at a repetition rate up to $10 \mathrm{~Hz}$ for the application with a rail accelerator load.

At this moment, explosive switches and mechanical switches are mainly used to interrupt very high currents [7], [8]. In explosive switches, explosives are used to break the conductor and to force the current into the load. After operation, the switch must be replaced. For operational purposes, it is obvious that explosive switches offer hardly any possibility for repetitive switching [9], [10].

Mechanical switches are the only type of switches able to conduct mega-ampere currents for a relative long period of time, as their resistance is a few micro-ohms and they have a high $\int i^{2} \mathrm{~d} t$-capability. However, opening a mechanical switch will cause an arc to occur between the contacts, which will dissipate a lot of energy and may damage the contacts. After a few cycles of operation, the contacts must be refurbished or replaced. To overcome this problem a counterpulse technique is applied. A counterpulse current, opposing the inductor current, is created in the opening switch. The net current flow through the switch will decrease and as soon as it reaches zero, the switch is opened, without any damage to the contacts.

There are different ways to create a counterpulse current in the opening switch: capacitively and inductively. In the capacitive way, the counterpulse current is created by discharging a capacitor bank via the opening switch. The inductive way uses a pulse transformer to inject the counterpulse current into the circuit [11].

Many different counterpulse circuits, utilizing a capacitor, have been studied [12]-[14]. In all these circuits, the capacitor experiences a voltage reversal during the counterpulse process. The capacitor has a high capacitance (up to several Farads) and is initially charged to a voltage of a few hundred volts up to a kilovolt. In circuits where the capacitor is in parallel to the opening switch and the load, the voltage may even become higher because of a high load voltage. All this means that the counterpulse capacitor bank is very big in mass and volume.

The resonant series counterpulse circuit described in this paper, utilizes the capacitor bank in such a way that there is no voltage reversal across the bank. This way, electrolytic capacitors can be used with the advantage of a relatively high energy density of $500 \mathrm{~J} / \mathrm{kg}$ at a voltage of about $450 \mathrm{~V}$, resulting in a relatively small mass and volume. The required

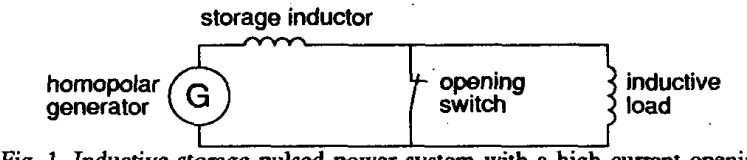

Fig. 1. Inductive storage pulsed power system with a high current opening switch. 


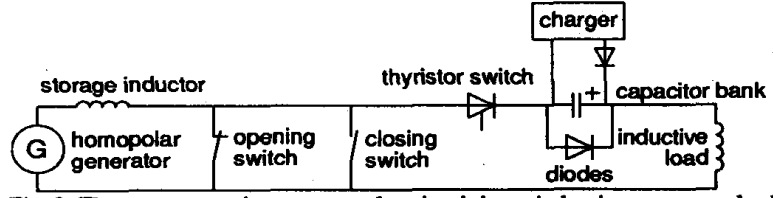

Fig. 2. The resonant series counterpulse circuit in an inductive storage pulsed power system.

initial voltage of the capacitor is only a few hundred volts. This makes counterpulse circuits for very high currents feasible to build.

Fig. 2 shows the generic resonant series counterpulse circuit. It consists of a capacitor bank with parallel diodes and a thyristor switch in series. This circuit is connected in series with the inductive load. The capacitor bank is charged to a specified voltage. The thyristor switch is open and blocking the capacitor voltage. The source current flows through the closed opening switch and there is no current through the load. At a certain moment, the thyristor switch is closed, leading to a resonance between the capacitor bank and the inductance of both the load and the opening switch. This resonant current flows through the load and the opening switch, opposing the current from the source. With appropriate values of the capacitance and voltage of the capacitor bank, the current in the opening switch is reduced to zero. At this moment, the opening switch is opened. The full source current now flows through the load and the capacitor, discharging it further. As the capacitor voltage crosses zero, the diodes start to conduct and take over the current. The capacitor voltage remains near zero.

A separate closing switch can be used to guarantee that the opening switch doesn't close at a high voltage imposed by the load, which causes arc erosion at the contacts of the opening switch. The closing switch is closed just before the opening switch is closed. After the opening switch has been closed, the capacitor bank is charged again and the circuit is ready for the next cycle.

Another advantage of the circuit is that there is no precurrent flowing through the load before the resonant current is activated. Normally, this is the case because of the resistive division of the source current between the opening switch and the load, causing heating of the load. In the resonant series counterpulse circuit, the thyristor switch prevents this.

At the moment, work is being performed at the Pulse Physics Laboratory to develop the resonant series counterpulse circuit for currents up to the mega-ampere level.

\section{ANALYSIS}

The whole process of counterpulsing the source current into the load and commutating it back to the opening switch is divided into six stages:

Stage I: The source current is flowing through the closed opening switch. If the closing switch had been closed during the previous cycle, it can be opened. The counterpulse capacitor bank is charged to a specified initial voltage.

Stage II: The thyristor switch is closed and the counterpulse is initiated. The load current, which is the counterpulse current, increases and the current through the opening switch decreases.

Stage III: The opening switch is opened at zero current. The load current equals the source current and the capacitor bank is further discharged. Its energy is transferred to the load.

Stage IV: The capacitor bank has been discharged and the diodes are conducting the load current.

Stage V: The closing switch is closed and the current starts to flow through it. The load current decreases.

Stage VI: The opening switch is closed and takes over the source current. The load current and the closing switch current both decrease to zero.

After stage VI, the circuit returns to stage I.

Each stage has been studied and some results of calculations are presented here. A number of assumptions are made for the calculations. The source current of the electrical energy source is considered to be constant. All resistances, inductances, and the capacitance of the capacitor bank are also considered to be constant. Switching actions are assumed to take place instantaneously.

\section{A. Stage I}

During this stage, the opening switch is closed and the total source current $I_{S}$ flows through it. The thyristor switch is open and the load current is zero. When the closing switch is still closed from the previous cycle, it can now be opened. The capacitor bank is charged during this stage to an initial voltage $U_{\text {ini. }}$. The voltage across the opening switch $u_{o s}$ is simply given by Ohm's law:

$$
u_{\mathrm{os}}=R_{\mathrm{os}} I_{\mathrm{S}} \text {, }
$$

where $R_{\mathrm{os}}$ is the resistance of the opening switch. This resistance depends on the contact area of the contacts and the contact pressure.

\section{B. Stage II}

This stage starts when the thyristor switch is triggered at

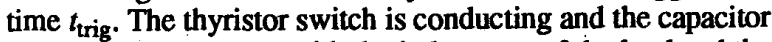
bank starts to resonate with the inductance of the load and the opening switch. The equivalent circuit for this stage is drawn in Fig. 3, with:

$i_{\mathrm{L}}$ : load current,

$i_{\text {os: }}$ current through the opening switch,

$u_{\mathrm{cp}}$ : voltage across the capacitance of the counterpulse capacitor bank,

$C_{\mathrm{cp}}$ : capacitance of the counterpulse capacitor bank,

$R_{\text {cp: }}$ equivalent series resistance of the counterpulse capacitor bank (ESR),

$L_{\text {cp }}$ : equivalent series inductance of the counterpulse capacitor bank (ESL),

$L_{\mathrm{os}}$ : inductance of the opening switch,

$L_{\mathrm{L}}$ : inductance of the load,

$R_{\mathrm{L}}$ : series resistance of the load,

$U_{\mathrm{T} 0}$ : threshold voltage of the thyristor switch,

$R_{\mathrm{T}}$ : resistance of the thyristor switch.

The following equations are derived from the circuit model:

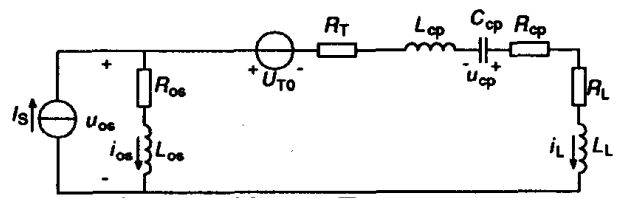

Fig. 3. Equivalent circuit model for stage II 


$$
\left\{\begin{aligned}
I_{\mathrm{S}}= & i_{\mathrm{os}}+i_{\mathrm{L}} \\
i_{\mathrm{L}}= & -C_{\mathrm{cp}} \frac{\mathrm{d} u_{\mathrm{cp}}}{\mathrm{d} t} \\
u_{\mathrm{cp}}= & \left(L_{\mathrm{L}}+L_{\mathrm{cp}}\right) \frac{\mathrm{d} i_{\mathrm{L}}}{\mathrm{d} t}+\left(R_{\mathrm{L}}+R_{\mathrm{cp}}+R_{\mathrm{T}}\right) i_{\mathrm{L}} \\
& \quad-R_{\mathrm{os}} i_{\mathrm{os}}-L_{\mathrm{os}} \frac{\mathrm{d} i_{\mathrm{os}}}{\mathrm{d} t}+U_{\mathrm{T} 0},
\end{aligned}\right.
$$

with the initial conditions:

$$
i_{\text {os }}\left(t_{\text {trig }}\right)=I_{\mathrm{S}}, i_{\mathrm{L}}\left(t_{\text {trig }}\right)=0 \text { and } u_{\mathrm{cp}}\left(t_{\text {trig }}\right)=U_{\text {ini }} \text {. }
$$

For the solution of (2) and (3), it is assumed that the total resistance in the circuit is smaller than the critical resistance:

$$
R_{\mathrm{tot}}<2 \sqrt{\frac{L_{\mathrm{tot}}}{C_{\mathrm{cp}}}},
$$

where $R_{\mathrm{tot}}=R_{\mathrm{os}}+R_{\mathrm{L}}+R_{\mathrm{cp}}+R_{\mathrm{T}}$ is the total resistance, and $L_{\mathrm{tot}}=L_{\mathrm{os}}+L_{\mathrm{L}}+L_{\mathrm{cp}}$ is the total inductance in the circuit. When (4) is valid, it means the waveforms are underdamped. This is usually the case. The solution of (2) and (3) is:

$$
\left\{\begin{array}{c}
i_{\mathrm{L}}(t)=\frac{U_{\mathrm{ini}}-U_{\mathrm{T} 0}+R_{\mathrm{os}} I_{\mathrm{S}}}{\beta L_{\text {tot }}} e^{-\alpha\left(t-t_{\text {trig }}\right)} \sin \left(\beta\left(t-t_{\text {trig }}\right)\right) \\
i_{\mathrm{os}}(t)=I_{\mathrm{S}}-i_{\mathrm{L}}(t) \\
u_{\mathrm{cp}}(t)=U_{\mathrm{T} 0}-R_{\mathrm{os}} I_{\mathrm{S}}+\left(U_{\mathrm{ini}}-U_{\mathrm{T} 0}+R_{\mathrm{os}} I_{\mathrm{S}}\right) e^{-\alpha\left(t-t_{\text {trig }}\right)} \\
\quad\left(\frac{\alpha}{\beta} \sin \left(\beta\left(t-t_{\text {trig }}\right)\right)+\cos \left(\beta\left(t-t_{\text {trig }}\right)\right)\right),
\end{array}\right.
$$

where $\alpha=R_{\mathrm{tot}} /\left(2 L_{\mathrm{tot}}\right)$ is the damping ratio, $\beta=\sqrt{\omega_{\mathrm{n}}{ }^{2}-\alpha^{2}}$ is the damped angular frequency and $\omega_{\mathrm{n}}=1 / \sqrt{L_{\mathrm{tot}} C_{\mathrm{cp}}}$ is the natural angular frequency.

The load current has a peak value $i_{\mathrm{L}, \mathrm{mm}}$ after time period $\Delta t_{\mathrm{mm}}$. This is obtained by taking the derivative of the load current and setting it to zero. This results in:

$$
\left\{\begin{array}{l}
i_{\mathrm{L}, \mathrm{mm}}=\frac{U_{\mathrm{ini}}-U_{\mathrm{T} 0}+R_{\mathrm{os}} I_{\mathrm{S}}}{\beta L_{\mathrm{tot}}} e^{-\alpha \Delta t_{\mathrm{mm}}} \sin \left(\beta \Delta t_{\mathrm{mm}}\right) \\
\Delta t_{\mathrm{mm}}=\frac{1}{\beta} \arctan \left(\frac{\beta}{\alpha}\right),
\end{array}\right.
$$

The unknowns in (6) are $C_{\mathrm{cp}}$ and $U_{\mathrm{ini}}$. When $i_{\mathrm{L}, \mathrm{mm}}$ and $\Delta t_{\mathrm{mm}}$ are known, they can be calculated using (6). We want the opening switch to open at zero current at a certain time $t_{\mathrm{oc}}$. The zero current will occur at $t_{\mathrm{oc}}$, when $C_{\mathrm{cp}}$ and $U_{\mathrm{ini}}$ are calculated with:

$$
i_{\mathrm{L}, \mathrm{mm}}=I_{\mathrm{S}} \text { and } \Delta t_{\mathrm{mm}}=t_{\mathrm{oc}}-t_{\text {trig }} \text {. }
$$

The capacitor voltage hasn't reached zero yet at $t_{o c}$ and is still positive. The current through the opening switch and the derivative of the load current are zero at $t_{\mathrm{oc}}$ and thus the voltages across the opening switch and inductances in Fig. 3 are zero. The capacitor voltage at $t_{\mathrm{oc}}$ is:

$$
u_{\mathrm{cp}}\left(t_{\mathrm{oc}}\right)=\left(R_{\mathrm{L}}+R_{\mathrm{cp}}+R_{\mathrm{T}}\right) I_{\mathrm{S}}+U_{\mathrm{TO}} \text {. }
$$

The voltage across the opening switch during stage II is found as:

$$
\begin{aligned}
u_{\mathrm{os}}(t) & =R_{\mathrm{os}} i_{\mathrm{os}}(t)+L_{\mathrm{os}} \frac{\mathrm{d} i_{\mathrm{os}}(t)}{\mathrm{d} t} \\
& =R_{\mathrm{os}}\left(I_{\mathrm{S}}-i_{\mathrm{L}}(t)\right)-L_{\mathrm{os}}\left(\frac{\beta}{\tan (\beta t)}-\alpha\right) i_{\mathrm{L}}(t) .
\end{aligned}
$$

At $t_{\circ}$, the voltage across the opening switch is zero.

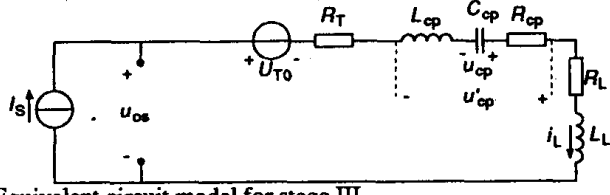

Fig. 4. Equivalent circuit model for stage III.

\section{Stage III}

This stage starts at $t_{\mathrm{oc}}$, when the opening switch is opened. The equivalent circuit model for this stage is given in Fig. 4. The load current is now equal to the source current and is constant.

The capacitor bank is further discharged by the source current. The capacitor voltage is:

$$
u_{\mathrm{cp}}(t)=u_{\mathrm{cp}}\left(t_{\mathrm{oc}}\right)-\frac{I_{\mathrm{S}}\left(t-t_{\mathrm{oc}}\right)}{C_{\mathrm{cp}}} \text {. }
$$

The voltage across the opening switch is, using (8) and (10):

$$
\begin{aligned}
u_{\mathrm{oS}}(t) & =U_{\mathrm{T} 0}-u_{\mathrm{cp}}(t)+\left(R_{\mathrm{L}}+R_{\mathrm{cp}}+R_{\mathrm{T}}\right) I_{\mathrm{S}} \\
& =\frac{I_{\mathrm{S}}\left(t-t_{\mathrm{oc}}\right)}{C_{\mathrm{cp}}} .
\end{aligned}
$$

This means that the RRRV (Rate of Rise of Recovery Voltage) that the opening switch must sustain, is:

$$
\mathrm{RRRV}=\frac{I_{\mathrm{S}}}{C_{\mathrm{cp}}}
$$

The actual voltage $u_{\mathrm{cp}}^{\prime}$ across the capacitor bank is:

$$
u_{\mathrm{cp}}^{\prime}(t)=u_{\mathrm{cp}}(t)-L_{\mathrm{cp}} \frac{\mathrm{d} i_{L}}{\mathrm{~d} t}-R_{\mathrm{cp}} i_{\mathrm{L}}=u_{\mathrm{cp}}(t)-R_{\mathrm{cp}} I_{\mathrm{S}} .
$$

When this voltage reaches zero at time $t_{\mathrm{cp}, 0}$, the diodes start to conduct. It is calculated using (10) and (13) that:

$$
t_{\mathrm{cp}, 0}=t_{\mathrm{oc}}+\frac{C_{\mathrm{cp}}}{I_{\mathrm{S}}}\left(u_{\mathrm{cp}}\left(t_{\mathrm{oc}}\right)-R_{\mathrm{cp}} I_{\mathrm{S}}\right)
$$

\section{Stage IV}

The circuit enters stage IV at $t_{\mathrm{cp}, 0}$. The diodes are conducting the full load current and the capacitor voltage remains at a low negative voltage:

$$
u_{\mathrm{cp}}^{\prime}=-\left(U_{\mathrm{D} 0}+R_{\mathrm{D}} I_{\mathrm{S}}\right) \text {, }
$$

where $U_{\mathrm{D} 0}$ is the threshold voltage of the diodes and $R_{\mathrm{D}}$ is the resistance of the diodes. The equivalent circuit model of this stage is given in Fig. 5 .

The voltage across the opening switch is:

$$
u_{\mathrm{os}}(t)=U_{\mathrm{T} 0}+U_{\mathrm{D} 0}+\left(R_{\mathrm{L}}+R_{\mathrm{T}}+R_{\mathrm{D}}\right) I_{\mathrm{S}} \text {. }
$$

\section{E. Stage $V$}

The closing switch is closed at time $t_{\mathrm{sc}, \mathrm{cs}}$. The load current decreases and the current in the closing switch increases. The voltage across the opening switch equals the voltage across the closing switch and is usually lower than the load voltage.

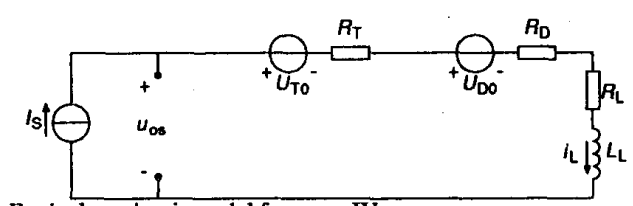

Fig. 5. Equivalent circuit model for stage IV. 


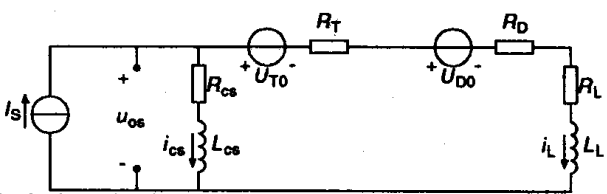

Fig. 6. Equivalent circuit model for stage $V$.

The equivalent circuit diagram is shown in Fig. 6, where $R_{\mathrm{cs}}$ and $L_{\mathrm{cs}}$ are the resistance and inductance of the closing switch and $i_{\mathrm{cs}}$ is the current through that switch.

The following equations are derived from Fig. 6:

$$
\left\{\begin{aligned}
I_{\mathrm{S}}=i_{\mathrm{cs}}+i_{\mathrm{L}} & \\
R_{\mathrm{cs}} i_{\mathrm{cs}}+L_{\mathrm{cs}} \frac{\mathrm{d} i_{\mathrm{cs}}}{\mathrm{d} t}=U_{\mathrm{T} 0} & +U_{\mathrm{D} 0}+\left(R_{\mathrm{L}}+R_{\mathrm{T}}+R_{\mathrm{D}}\right) i_{\mathrm{L}} \\
& +L_{\mathrm{L}} \frac{\mathrm{d} i_{\mathrm{L}}}{\mathrm{d} t},
\end{aligned}\right.
$$

with initial conditions:

$$
i_{\mathrm{L}}\left(t_{\mathrm{sc}, \mathrm{cs}}\right)=I_{\mathrm{S}} \text { and } i_{\mathrm{cs}}\left(t_{\mathrm{sc}, \mathrm{cs}}\right)=0 \text {. }
$$

The solution of (17) and (18) is:

$$
\left\{\begin{aligned}
i_{\mathrm{cs}}(t)= & \left(\frac{\left(R_{\mathrm{T}}+R_{\mathrm{D}}+R_{\mathrm{L}}\right) I_{\mathrm{S}}+U_{\mathrm{T} 0}+U_{\mathrm{D} 0}}{R_{\mathrm{cs}}+R_{\mathrm{T}}+R_{\mathrm{D}}+R_{\mathrm{L}}}\right) \\
& \left(1-e^{-\left(t-t_{\mathrm{sc}, \mathrm{cs}}\right) / \tau}\right) \\
i_{\mathrm{L}}(t)= & I_{\mathrm{S}}-i_{\mathrm{cs}}(t),
\end{aligned}\right.
$$

where $\tau$ is the time constant of the exponential decay:

$$
\tau=\frac{L_{\mathrm{cs}}+L_{\mathrm{L}}}{R_{\mathrm{cs}}+R_{\mathrm{T}}+R_{\mathrm{D}}+R_{\mathrm{L}}} .
$$

The voltage across the opening switch is:

$$
\begin{aligned}
u_{\mathrm{os}}(t)= & R_{\mathrm{cs}} i_{\mathrm{cs}}+L_{\mathrm{cs}} \frac{\mathrm{d} i_{\mathrm{cs}}}{\mathrm{d} t} \\
= & \left(\left(R_{\mathrm{T}}+R_{\mathrm{D}}+R_{\mathrm{L}}\right) I_{\mathrm{S}}+U_{\mathrm{T} 0}+U_{\mathrm{D} 0}\right) \\
& \left(\frac{R_{\mathrm{cs}}\left(1-e^{-\left(t-t_{\mathrm{sc}, \mathrm{cs}}\right) / \tau}\right)}{R_{\mathrm{cs}}+R_{\mathrm{T}}+R_{\mathrm{D}}+R_{\mathrm{L}}}+\frac{L_{\mathrm{cs}} e^{-\left(t-t_{\mathrm{sc}, \mathrm{cs}}\right) / \tau}}{L_{\mathrm{cs}}+L_{\mathrm{L}}}\right) .
\end{aligned}
$$

The resistance and inductance of the closing switch are lower than the total resistances and inductances in the load circuit. Equations (16) and (21) show that the voltage across the opening switch at the moment the closing switch is closed, is a factor $L_{\mathrm{cs}} /\left(L_{\mathrm{cs}}+L_{\mathrm{L}}\right)$ lower than at the moment just before the closing switch is closed.

\section{F. Stage VI}

Stage VI starts when the opening switch is closed at time $t_{\mathrm{sc}, \mathrm{os}}$. This can be shortly after time $t_{\mathrm{sc}, \mathrm{cs}}$, so that the current in the closing switch remains low. The equivalent circuit model for this stage is given in Fig. 7.

The load resistance is much higher than the resistances of the opening and the closing switch. It even goes to infinity, as is the case with rail accelerators when the projectile exits. The

Fig. 7. Equivalent circuit model for stage VI. load current will decrease rapidly to zero. The current in the closing switch will decay exponentially and the current in the opening switch will increase exponentially to the values of:

$$
i_{\mathrm{cs}}=\frac{R_{\mathrm{os}}}{R_{\mathrm{os}}+R_{\mathrm{cs}}} I_{\mathrm{S}} \text { and } i_{\mathrm{os}}=\frac{R_{\mathrm{cs}}}{R_{\mathrm{os}}+R_{\mathrm{cs}}} I_{\mathrm{S}} \text {. }
$$

When the resistance of the closing switch is relatively high compared to the resistance of the opening switch, the current in the closing switch will be low and it can be opened. This returns the circuit into stage $I$.

\section{G. Waveforms}

Fig. 8 shows the waveforms of the circuit. They are obtained from the equations given for the different stages. The stages are depicted by their Roman numerals.

\section{THE COMPONENTS}

We will now discuss the components of the resonant series counterpulse circuit.

\section{A. The Opening Switch}

The opening switch must conduct the full source current for a relatively long period. This can be a current of a megaampere for several hundreds of milliseconds. Therefore, the switch must have a very low resistance and a high $\int i^{2} \mathrm{~d} t$ capability. It must be able to open at zero or low current (smaller than $50 \mathrm{kA}$ ) and sustain the RRRV given by (12). When the switch is open, it must be able to withstand the voltage given by (16). That can be up to several kilovolts, depending on the load. When a separate closing switch is used, the opening switch can close at a relatively low voltage, as discussed in section II.E. The most suitable switches are mechanical switches [4], [7].

\section{$B$. The Closing Switch}

The function of the closing switch is to lower the voltage across the opening switch, so that the opening switch is closed without arc erosion at its contacts. Therefore, the closing switch must have a very low inductance, so that the voltage just after closing is low. The resistance of the closing switch must be high compared to the resistance of the opening switch. This way the current in the switch remains low and it is opened at low current. The $\int i^{2} \mathrm{~d} t$-capability is much lower than that of the opening switch. The closing switch must withstand the same voltage as the opening switch.

If a rail accelerator is used as a load, the closing switch is closed at such a moment that the rail current is relatively low when the projectile exits, in order to prevent a muzzle flash to
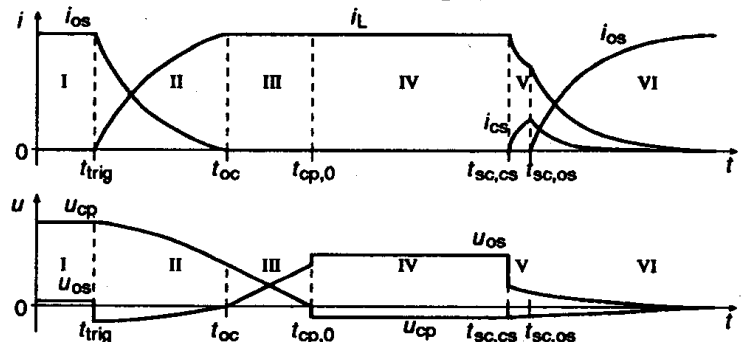

Fig. 8. Waveforms of the resonant series counterpulse circuit; upper graph: current through the opening switch $\left(i_{\text {os }}\right)$, the load $\left(i_{\mathrm{L}}\right)$ and the closing switch $\left(i_{\mathrm{cs}}\right)$; lower graph: voltage across the opening switch $\left(u_{o s}\right)$ and the counterpulse capacitor $\left(u_{\mathrm{cp}}\right)$. 
occur. A sensor measuring the position of the projectile in the rail accelerator can be used to determine that moment and to generate a trigger signal for the closing switch. The latter must have a fast response (better than $10 \mu \mathrm{s}$ ) so that not too much rail accelerator length is wasted. A thyristor is a good candidate because of its fast switching action.

\section{The Thyristor Switch}

As the name already implies, thyristors are used for this switch. It must be able to block the initial voltage of the counterpulse capacitor bank, which may be only several hundred volts. It has to conduct the full source current for the pulse duration, usually a few milliseconds. The maximum $\mathrm{d} i / \mathrm{d} t$ that the switch must sustain, is derived from (5):

$$
\left(\frac{\mathrm{d} i}{\mathrm{~d} t}\right)_{\max }=\frac{\mathrm{d} i_{\mathrm{L}}\left(t_{\text {trig }}\right)}{\mathrm{d} t}=\frac{U_{\mathrm{ini}}-U_{\mathrm{TO}}+R_{\mathrm{os}} I_{\mathrm{S}}}{L_{\mathrm{tot}}} .
$$

Depending on the source current, a number of thyristors will have to be used in parallel.

\section{The Counterpulse Capacitor Bank}

The counterpulse capacitor bank can be constructed of electrolytic capacitors. The capacitance of the capacitor bank needs to be several farads in our case, and therefore a large number of electrolytic capacitors must be put in parallel Each capacitor will have a diode directly connected at its terminals, so that the negative voltage across the capacitors remains as low as possible, when the diodes are conducting. The diodes have to conduct the full source current. There are as many diodes as capacitors and thus one diode only has to conduct a small part of the source current, a few kiloamperes.

If more than one thyristor is used, the capacitor bank can consist of modules of parallel capacitors, with each module in series with a thyristor.

\section{The LoAD, A SPECIAl CASE: THE RaIl ACCElERATOR}

The resistances and inductances are considered to be constant for the analysis. However, there are loads that do not have a constant resistance and inductance, such as the rail accelerator. When the projectile moves along the rails of the rail accelerator, the resistance and inductance increase and an electromotive force is generated.

Fig. 9 shows a simple equivalent circuit model of a rail accelerator. $u_{\mathrm{br}}$ is the breech voltage. $R^{\prime}$ and $L^{\prime}$ are the resistance and inductance per unit length and $E$ is the electromotive force. $R^{\prime}$ and $L^{\prime}$ depend on the time and current distribution. $R_{\mathrm{arm}}$ is the resistance of the armature of the projectile and also depends on the time and current distribution and whether or not plasma is formed during the acceleration. $x$ and $v$ are the position and velocity of the projectile. They are determined by:

$$
\begin{aligned}
& F_{\mathrm{L}}=\frac{1}{2} L^{\prime} i_{\mathrm{L}}^{2}(t), a(t)=\frac{F_{\mathrm{L}}-F_{\text {fric }}}{m}, v(t)=\int_{t_{\mathrm{v}}}^{t} a(t) \mathrm{d} t \text { and } \\
& x(t)=x_{0}+\int_{t_{\mathrm{v}}}^{t} v(t) \mathrm{d} t
\end{aligned}
$$

where $F_{\mathrm{L}}$ is the Lorentz force, $a$ is the acceleration, $F_{\text {fric }}$ is the friction force, $m$ is the mass of the projectile, $t_{\mathrm{v}}$ is the time

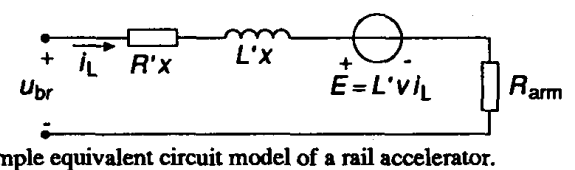

Fig. 9. Simple equivalent circuit model of a rail accelerator.

that the projectile starts to accelerate and $x_{0}$ is the initial position of the projectile.

The projectile may start to accelerate at a current lower than the full source current. That means it will start already when the counterpulse process is still in stage II. This results in an equation for the load current:

$$
\begin{aligned}
& \left(L_{\mathrm{os}}+L_{\mathrm{cp}}+L^{\prime} x\right) \frac{\mathrm{d}^{2} i_{\mathrm{L}}}{\mathrm{d} t^{2}}+\left(R^{\prime} v+L^{\prime} a+\frac{1}{C_{\mathrm{cp}}}\right) i_{\mathrm{L}} \\
& \quad+\left(R_{\mathrm{os}}+R_{\mathrm{T}}+R_{\mathrm{cp}}+R_{a r m}+R^{\prime} x+2 L^{\prime} v\right) \frac{\mathrm{d} i_{\mathrm{L}}}{\mathrm{d} t}=0,
\end{aligned}
$$

with the initial conditions:

$$
\begin{aligned}
& \begin{aligned}
& i_{\mathrm{L}}\left(t_{\mathrm{v}}\right)=I_{\mathrm{v}} \text { and } \\
& \frac{\mathrm{d} i_{\mathrm{L}}\left(t_{\mathrm{v}}\right)}{\mathrm{d} t}= \frac{u_{\mathrm{cp}}\left(t_{\mathrm{v}}\right)+R_{\mathrm{os}} I_{\mathrm{s}}-U_{\mathrm{T} 0}}{L_{\mathrm{cp}}+L_{\mathrm{os}}+L^{\prime} x_{0}} \\
&-\frac{\left(R_{\mathrm{os}}+R_{\mathrm{T}}+R_{\mathrm{cp}}+R_{a r m}+R^{\prime} x_{0}\right) I_{\mathrm{v}}}{L_{\mathrm{cp}}+L_{\mathrm{os}}+L^{\prime} x_{0}} .
\end{aligned}
\end{aligned}
$$

where $I_{\mathrm{v}}$ is the current at which the projectile starts to accelerate. Given $I_{\mathrm{v}}, t_{\mathrm{v}}$ and $u_{\mathrm{cp}}\left(t_{\mathrm{v}}\right)$ can be calculated with (5).

The peak value of the load current and the corresponding time will be smaller than the values calculated with (6). A higher capacitance and initial capacitor voltage than calculated there, must be used. It is not possible to obtain an explicit expression for $C_{\mathrm{cp}}$ from (25), and therefore, a numerical method must be used.

Fig. 10 shows the counterpulse waveforms resulting from simulations for $1 \mathrm{MA}$ full source current. The following values are used: $L_{\mathrm{os}}=20 \mathrm{nH}, R_{\mathrm{os}}=2 \mu \Omega, U_{\mathrm{T} 0}=0.86 \mathrm{~V}$, $R_{\mathrm{T}}=20 \mu \Omega, C_{\mathrm{cp}}=6.32 \mathrm{~F}, R_{\mathrm{cp}}=20 \mu \Omega, L_{\mathrm{cp}}=30 \mathrm{nH}$, $U_{\mathrm{D} 0}=0.7 \mathrm{~V}, R_{\mathrm{D}}=10 \mu \Omega, R^{\prime}=100 \mu \Omega / \mathrm{m}, L^{\prime}=0.4 \mu \mathrm{H} / \mathrm{m}$, $R_{\mathrm{amm}}=18 \mu \Omega, x_{0}=0.1 \mathrm{~m}, m=100 \mathrm{~g}$, The friction force is $15 \%$ of the Lorentz force. The source has been modelled as an inductor of $6.7 \mu \mathrm{H}$ with a resistance of $23 \mu \Omega$ and an initial current of $1 \mathrm{MA}$. The length of the rail accelerator is $5 \mathrm{~m}$.

Fig. 10(a) shows the waveforms in the case the projectile remains fixed in the rail accelerator. The inductance and resistance of the rail accelerator are constant. The thyristor switch is triggered at $3 \mathrm{~ms}$ and the opening switch is opened at $4 \mathrm{~ms}$. The closing switch is closed at $5.3 \mathrm{~ms}$ and the opening switch at $5.5 \mathrm{~ms}$. Using the same values as for Fig. 10(a), the waveforms of Fig. 10(b) result when the projectile starts to accelerate at a current $I_{\mathrm{v}}$ equal to $200 \mathrm{kA}$. The peak value of the load current is $30 \%$ lower and occurs earlier than in Fig. 10(a), so that the opening switch has to open at a high current. The projectile leaves the rail accelerator at $6.3 \mathrm{~ms}$, as can be seen by the sudden increase in both the opening switch current and the closing switch current. In Fig. 10(c) the initial voltage has been changed, so that the opening switch opens at a zero current. The time interval $t_{\text {oc }} t_{\text {trig }}$ is now smaller. The thyristor switch is triggered at $3.53 \mathrm{~ms}$. Note that in this case stage IV doesn't occur in Fig. 10(c). The circuit is already in stage VI, when the capacitor voltage reaches zero and the diodes start to conduct. 


\section{CONCLUSIONS}

A resonant series counterpulse technique has been described and analysed. It can assist a mechanical opening switch for pulsed power applications in the controlled

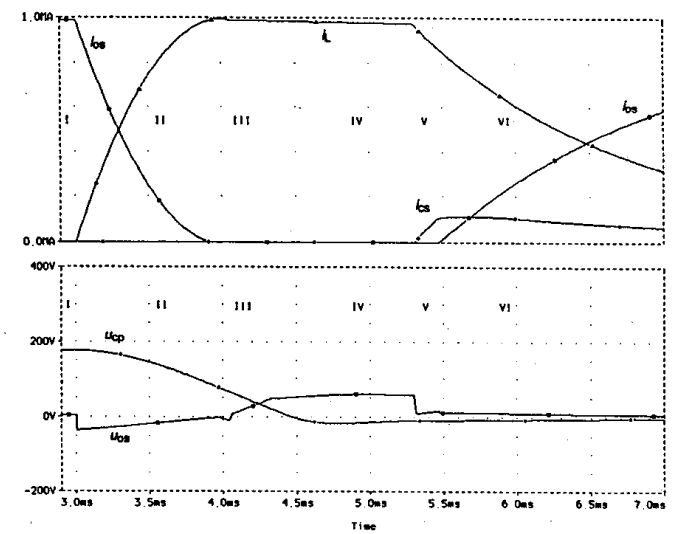

(a). Projectile is fixed; $U_{\mathrm{ini}}=176 \mathrm{~V}, t_{\mathrm{oc}}{ }^{-t_{\text {trig }}}=1 \mathrm{~ms}$.
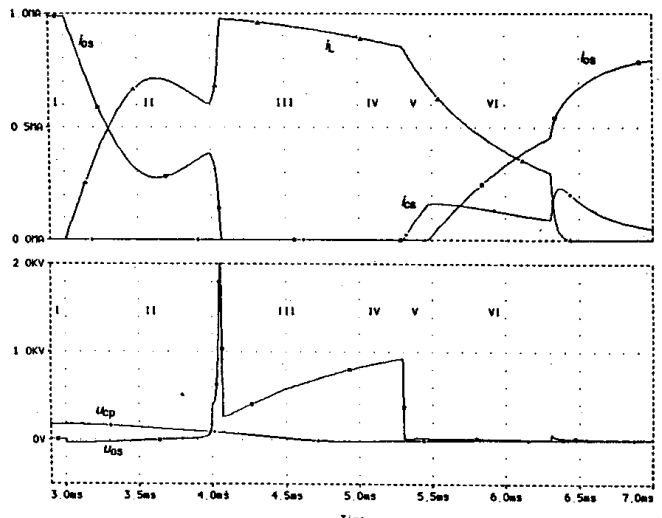

(b). Projectile motion starts at $200 \mathrm{kA} ; U_{\text {ini }}=176 \mathrm{~V}, t_{\text {oc }}{ }^{-t_{\text {trig }}}=1 \mathrm{~ms}$.

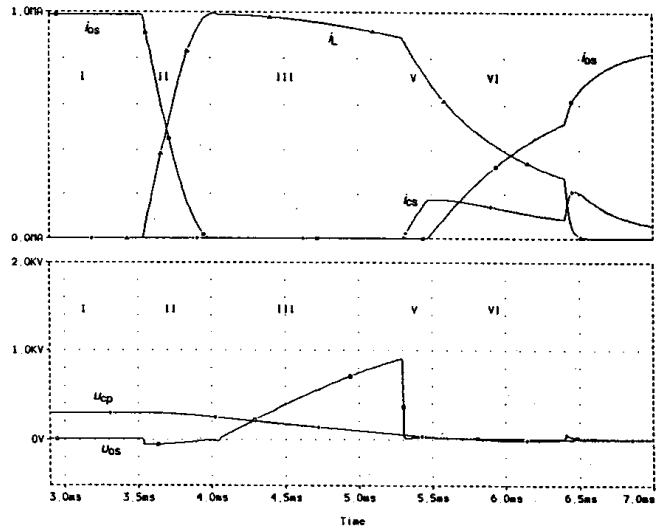

(c). Projectile motion starts at $200 \mathrm{kA} ; U_{\text {ini }}=295 \mathrm{~V}, t_{\mathrm{oc}}{ }^{-t_{\text {trig }}}=0.47 \mathrm{~ms}$.

Fig. 10. Counterpulse waveforms using a rail accelerator as a load; upper graphs: current through the opening switch $\left(i_{\text {oss }}\right)$, the load $\left(i_{\mathrm{L}}\right)$ and the closing switch $\left(i_{c s}\right)$; lower graphs: voltage across the opening switch $\left(u_{o s}\right)$ and the counterpulse capacitor $\left(u_{\mathrm{cp}}\right)$. interruption of currents at the mega-ampere level. The circuit uses a pre-charged capacitor bank and a thyristor switch in series with the inductive load to create a resonant counterpulse current in the mechanical opening switch. In this way, the opening switch can be opened at a low or zero current. A separate closing switch prevents closing of the opening switch at high voltage. The advantage for operation of the mechanical opening switch at low current and low voltage is that no arc erosion occurs at the contacts.

Compared to other counterpulse circuits [12], [13], the advantage of the technique described here is that the counterpulse capacitor bank does not experience a voltage reversal. Therefore, electrolytic capacitors, which have a high energy density, can be applied. The remaining energy of the capacitor after the opening switch has been opened, is transferred to the load. The required initial voltage of the capacitor is only a few hundred volts, whereas it may be above a kilovolt in other circuits.

Another advantage is that the load does not experience a pre-current, which causes unwanted pre-heating.

At the moment, the resonant series counterpulse technique for the interruption of currents up to the mega-ampere level is being developed for rail accelerator applications at the Pulse Physics Laboratory.

\section{ACKNOWLEDGMENT}

The authors thank Prof. J.A. Schot, Dr. J.B. Klaassens of the Laboratory for Power Electronics and Electrical Machines of the Delft University of Technology and Dr. W.J. Kolkert of TNO PML-Pulse Physics for their encouragement and support.

\section{REFERENCES}

[1] H. Knoepfel, Pulsed High Magnetic Fields, North-Holland Publishing Company, 1970.

[2] M. Kristiansen and K.H. Schoenbach, Eds., Final Report on Workshop on Repetitive Opening Switches, Tamamon, 1981.

[3] K.H. Schoenbach, M. Kristiansen and G. Schaefer, "A review of opening switch technology for inductive energy storage", Proc. IEEE, vol. 72, pp. 1019-1040, August 1984

[4] E.J. Clothiaux, A.K. Hyder and M. Kristiansen, Eds., Workshop on High Current Opening Switches for EML Applications, Tamarron, 1986.

[5] T. McCormick and J. Barber, "A $500 \mathrm{kA}$ repetitive opening switch", IEEE Trans. Magn., vol. 22, pp. 1613-1618, November 1986

[6] E. Tuinman, "The compact pulsed homopolar generator facility at PML,-Pulse Physics". Proc. Ist European Symposium on EML Technology, Delft, September 1988

[7] B.M. Rech and R.C. Zowarka, Jr., "Design and construction of a twostage opening switch", IEEE Trans. Magn., vol. 22, pp. 1706-1711, November 1986.

[8] J.P. Barber, "Advances in opening switch technology at IAP research", IEEE Trans. Magn., vol. 25, pp. 68-71, January 1989.

[9] E. Aivaliotis and $M$. Peterhans, "Explosive opening switch work at Westinghouse", IEEE Trans. Magn., vol. 25, pp. 40-45, January 1989.

[10] R.D. Ford, D.J. Jenkins, W.H. Lupton, R.B. Klug, D.B. Jensen and J. Scanlon, "A repetitive switching array for laboratory electromagnetic launcher research", Dig. 7th IEEE International Pulsed Power Conf. pp. 156-159, 1989.

[11] E.M.W. Leung, R.E. Bailey and P.H. Michels, "Using a small hybrid pulse power transformer unit as component of a high-current opening switch for a railgun", IEEE Trans. Magn., vol. 25, pp. 1779-1782, March 1989.

[12] E.M. Honig, Repetitive Energy Transfers from an Inductive Energy Store. Los Alamos National Laboratory, Report no. LA-10238-T, Los Alamos, 1984.

[13] M.E. Parten, "Computer simulation of a repetitive energy transfer system", IEEE Trans. Magn, vol. 22, pp. 1645-1647, November 1986.

[14] M.A.M. Kaanders, W.H.P. Mosterdijk and P. van Gelder, "Status of the Kapitza facility at TNO PML-Pulse Physics", Dig. 9th IEEE International Pulsed Power Conf., 1993. 